\title{
ALFABETIZAÇÃO DE ALUNOS COM DEFICIÊNCIA INTELECTUAL A PARTIR DE METODOLOGIAS ATIVAS
}

\section{Literacy of intellectual disability students from active methodologies}

\author{
Édna Leandro da Silva - Universidade Federal de Mato Grosso do Sul /Brasil \\ Nelson Dias- Universidade Federal de Mato Grosso do Sul /Brasil
}

\begin{abstract}
RESUMO: O presente escrito tem o objetivo de revisar a literatura disponível acerca das possibilidades metodológicas para alfabetização de estudantes com deficiência intelectual. Nessa perspectiva as metodologias ativas se apresentam como possibilidades flexíveis para adaptações nesse processo. Dessa forma, foi realizada uma revisão de literatura em produções disponíveis no Catalogo de Teses \& Dissertações da Capes, utilizando pesquisa de cunho exploratório. Nesse segmento foram pesquisados os seguintes descritores: "metodologias ativas, alfabetização, estudantes com deficiência intelectual". Foram encontrados dois tipos de metodologias ativas que tratam especificamente da alfabetização do público alvo nos últimos cinco anos; o jogo e a instrução por pares nos últimos cinco anos, uma sobre o jogo como metodologia ativa para alfabetização e a intrução por pares. A abordagem teórica desse escrito se pauta na teoria histórico-cultural, através da interação social para ensino aprendizagem, preconizada por Lev Vygotsky (1896-1934). Os resultados desse trabalho, apresentam duas possibilidades de adaptações das metodologias ativas como estratégia para alfabetização de estudantes com deficiência intelectual.
\end{abstract}

Palavras-chave: Metodologias Ativas. Alfabetização. Estratégias de Ensino Aprendizagem.

ABSTRACT: This paper aims to review the available literature about the methodological strategies for literacy of students with intellectual disabilities. From this perspective, active methodologies present themselves as flexible possibilities for adaptations in this process. Thus, a literature review was performed on productions available in the Capes Thesis \& Dissertations Ccatalogo, using exploratory research. In this segment were searched the following descriptors "active methodologies, literacy students with intellectual disabilities". We found two types of active methodologies that specifically address target audience literacy in the last five years, gambling and peer education, in the last five years, one about gambling as an active methodology for literacy and peer education. The theoretical approach of this writing is based on historical-cultural theory, through social interaction for teaching and learning, advocated by Lev Vygotsky (18961934). The results of this work present two possibilities of adaptations of active methodologies as a strategy for literacy of students with intellectual disabilities.

Keywords: Active Methodologies. Literacy. Teaching Strategies Learning.

\section{INTRODUÇÃO}

Educação, Psicologia e Interfaces, Volume 3, Dossiê Inclusão e Diversidade, p. 23-36, 2019.

ISSN: 2594-5343. DOI: https://doi.org/10.37444/issn-2594-5343.v3i4.198 
A presente produção trata da alfabetização de estudantes com deficiência intelectual e busca apresentar a produção do conhecimento acerca do assunto a partir de produções do conhecimento disponíveis na base de dados do Catalogo de Teses \& Dissertaçoes da Capes.

Atualmente, pesquisas apontam que técnicas e metodologias tradicionais não são mais suficientes para um trabalho pedagógico eficaz para o ensino da linguagem escrita para estudantes com deficiência intelectual. Nessa perspectiva, as metodologias ativas surgem como possibilidades estratégicas de metodologias e técnicas para esse processo.

A problemática que se apresenta pode ser encontrada na tese de Pereira (2018), que mostra a dúvida de professores sobre como seguir as Diretrizes Normativas acerca das adaptações a serem realizadas no trabalho pedagógico para alfabetização de estudantes com deficiência intelectual. Segundo Pereira (2018, p. 34), pesquisas já realizadas sobre a temática apontam que há dificuldades para as adaptações de pequeno e grande porte.

Dessa forma, se apresenta os resultados da produção do conhecimento de uma revisão de literatura a partir da pesquisa exploratória e dessa forma apresenta dentre diversas possibilidades de metodologias ativas, duas opções de como fazer adaptações disponíveis em teses e dissertações que tiveram como tema, tipos de metodologias ativas possíveis para o processo de alfabetização de estudantes com deficiência intelectual.

\subsection{Metodologias Ativas}

O conceito da metodologia ativa está no desenvolvimento de atividades orientadas antes do momento em que ela será desenvolvida. Os textos que serão discutidos em conjunto na sala de aula bem como vídeos, figuras ou palestras possibilitarão o levantamento de hipóteses para resolução de possíveis problemas como explica (BERGMANN; SAMS. 2012, p. 34):

Em uma aula tradicional os alunos são expostos a um conteúdo em sala e podem fazer exercícios em casa, é aí que ocorre uma inversão nas coisas. Na aula invertida o aluno estuda o assunto antes da aula por meio de materiais como vídeos indicados pelo professor depois ele deve ir a aula para aplicar o que aprendeu em exercícios propostos pelo professor, as grandes vantagens e que cada aluno pode aprender no seu próprio ritmo podendo pausar ou assistir de novo o vídeo indicado pelo

Educação, Psicologia e Interfaces, Volume 3, Dossiê Inclusão e Diversidade, p. 23-36, 2019.

ISSN: 2594-5343. DOI: https://doi.org/10.37444/issn-2594-5343.v3i4.198 
professor e caso tenha dificuldade para realizar ele poderá contar com o professor e os outros colegas.

A aprendizagem centrada no aluno funciona como centro organizador da proposta pedagógica e estímulo para o aluno buscar conhecimento; “[...] alunos como elaboradores de soluções e participantes ativos do processo de gerar ideias novas e compartilhá-las com os demais e os professores como facilitadores" (AGUIAR. 2008, p. 49).

A colaboração, a interação, a comunicação, a cooperação no trabalho coletivo proporciona aprendizagem significativa aos estudantes, os grupos encontram caminhos alternativos com mais facilidades para desenvolver as habilidades necessárias a partir do levantamento de hipóteses, dando liberdade aos estudantes para que construam meios, afim de alcançar objetivos propostos

No ensino tradicional, o professor se assume como o centro do aprendizado, ou seja, possui o papel de detentor do conhecimento que transmite o conhecimento em forma de monólogo, sem levar em consideração os conhecimentos prévios, as vivências, características sociais, culturais e as perspectivas históricas e culturais, dos estudantes.

Nos últimos anos, esse tipo de prática tem sofrido críticas, visto que, não coloca o educando como sujeito de sua própria aprendizagem o que acaba colocando-o como um ser passivo de aprendizagem, ou como uma tabula rasa como se coaduna com estudos de Piaget (1990).

As metodologias ativas colocam os estudantes num papel ativo na construção da aprendizagem, suas características são métodos de ensino de incentivadores sinta-se responsável pela busca e levantamento de hipóteses acerca das atividades a serem desenvolvidas pelos educadores. Isso não quer dizer que as metodologias ativas são melhores do que as tradicionais, mas que há possibilidade de complementação. Uma aprendizagem que estimula a participação dos alunos durante as aulas, os envolvem na construção do conhecimento quando relacionados aos desafios cotidianos.

Essas estratégias preparam os estudantes para as responsabilidades pessoais, profissionais e sociais a partir de seus conhecimentos prévios (senso comum) para organização na resolução de conflitos cotidianos.

Ao complementar o ensino com as metodologias ativas, o estudante não fica apenas ouvindo o monólogo de conhecimentos dos professores, tentando assimilar conteúdo apresentados, ele participa das aulas de forma ativa a partir do estimulo à 
reflexão e ao debate sobre determinado assunto, como caracteriza (FREITAS. 2015, p. 118):

As metodologias ativas se caracterizam por colocar o estudante no centro do processo de ensino-aprendizagem, tornando-o construtor do seu próprio conhecimento por meio de um currículo que agrega as diferentes disciplinas, permitindo que ele desenvolva um olhar amplo acerca do ser humano, nas suas relações com a sociedade e com o ambiente.

Alunos com deficiência intelectual, com grau considerado leve da deficiência, têm dificuldades na aquisição de conhecimentos básicos (conceitual, social, praticas que exigem coordenação motora, intelectual, emocional e em diversos casos no desenvolvimento da linguagem oral) devido ao comprometimento cognitivo.

A psicologia histórico-cultural parte do principio de que os símbolos, gestos e a linguagem oral são pontos de partida fundamental para a aquisição da aprendizagem da linguagem escrita, no entanto esses pontos comumente são alterados pela deficiência, tornando mais difícil a construção de estratégias de ensino. Por isso, se compreende que a utilização de metodologias ativas propõe novas possibilidades.

\section{MATERIAL E MÉTODO}

A presente revisão de literatura utilizou como descritores: alfabetizaçãodeficiência intelectual - metodologias ativas. Dessa forma foi realizado o refinamento nas bsucas acerca dos tipos de trabalho que poderiam ser teses ou dissertações, na grande área de conhecimento, avaliação e concentração: Educação.

Foram utilizados como critérios de exclusão o lócus das pesquisas e as modalidades de ensino, porque há diversas produções além da sala de aula, por exemplo em projetos de educação não formal ou Salas de Recursos Multifuncionais, ou instituições de ensino especializadas. Em relação às modalidades de ensino, há utilização de metodologias ativas na educação indígena, quilombola e especial e Educação de Jovens e Adultos.

Aplicando os critérios de exclusão, no primeiro momento foram analisados os títulos das produções e nos resumos os objetivos gerais e os resultados buscando a alfabetização de estudantes com deficiência intelectual nos anos iniciais do ensino fundamental em salas comuns do ensino regular.

Educação, Psicologia e Interfaces, Volume 3, Dossiê Inclusão e Diversidade, p. 23-36, 2019. 
A busca utilizou pesquisas disponíveis no Catálogo de Teses \& Dissertações da Capes, priorizando produções do conhecimento nos últimos cinco anos, acerca das possibilidades de utilização das metodologias ativas como estratégia na alfabetização de estudantes com deficiência intelectual.

Nessa perspectiva foi realizada a pesquisa exploratória que "[...] constitui a primeira etapa de uma investigação mais ampla. Quando o tema escolhido é bastante genérico, se torna necessário o esclarecimento e delimitação, o que exige revisão da literatura, discussão com especialistas e outros procedimentos” (GIL. 2008, p. 27):

As pesquisas exploratórias têm como principal finalidade desenvolver, esclarecer e modificar conceitos e idéias, tendo em vista a formulação de problemas mais precisos ou hipóteses pesquisáveis para estudos posteriores. De todos os tipos de pesquisa, estas são as que apresentam menor rigidez no planejamento. Habitualmente envolvem levantamento bibliográfico e documental, entrevistas não padronizadas e estudos de caso. Procedimentos de amostragem e técnicas quantitativas de coleta de dados não são costumeiramente aplicados nestas pesquisas (GIL. 2008, p. 29).

Os fundamentos teóricos e metodológicos preconizam a abordagem interacionaista de Lev Vygotsky (1896-1934) que valoriza a interação professor e aluno, aluno e aluno no processo de ensino aprendizagem, nesse processo as metodologias ativas compreende estratégias didáticas centralizada, efetivamente, no estudante. O que contraria o método tradicional de ensino, cuja representação do livro didático e centralização na ação intelectual do professor são fontes exclusivas do saber na sala de aula (PEREIRA. 2012).

Com as metodologias ativas, os estudantes aprendem cerca de dez por cento lendo; vinte por cento escrevendo; cinquenta por cento observando e escutando; setenta por cento discutindo com outras pessoas; oitenta por cento praticando; e noventa e cinco por cento ensinando (PEREIRA. 2012). Dessa forma é possível observar as contribuições do interacionismo, visto que considera o aluno "[...] um sujeito ativo que, para construir seus conhecimentos, se apropria dos elementos fornecidos pelos professores, pelos livros didáticos, pelas atividades realizadas em sala e por seus colegas" (Oliveira, 2010, p. 28).

\section{RESULTADOS E DISCUSSÃO}

Educação, Psicologia e Interfaces, Volume 3, Dossiê Inclusão e Diversidade, p. 23-36, 2019.

ISSN: 2594-5343. DOI: https://doi.org/10.37444/issn-2594-5343.v3i4.198 
Os descritores utilizados para identificar metodologias ativas para alfabetização foram "alfabetização de alunos com deficiência intelectual a partir de metodologias ativas". Os resultados com esses termos foram duas dissertações, a primeira analisada doi a dissertação de Carvalho (2015) “O Jogo Como Recurso Para O Ensino Da Leitura A Estudantes Com Deficiência Intelectual" que teve o objetivo de aplicar atividades lúdicas que focassem na aprendizagem da leitura.

Os resultados apontaram que ao conciliar atividades de leitura com um jogo de tabuleiro, conseguimos fazer com que os discentes desenvolvessem estratégias de leitura, usassem seus conhecimentos prévios e, ampliassem sua compreensão sobre o ato de ler. Portanto as possibilidades encontradas aqui é o jogo de tabuleiro "batalha silábica" como ferramenta pedagógica.

A segunda foi a dissertação "Ditado Digital: O Erro Como Parte do Processo de aprendizagem" de (DEITOS, 2018), utilizou além do jogo, novas tecnologias de informação e comunicação. A pesquisa encontrada se coaduna com esse estudo, pois aborda:

\begin{abstract}
A tecnologia aplicada à educação a partir de um jogo digital de ditado, em que o principal objetivo é auxiliar a aprendizagem da escrita e da ortografia de crianças do Ensino Fundamental I, abordando o benefício que a atividade tradicional do ditado traz ao ser inserida no contexto tecnológico. Para isso a metodologia aplicada trata-se de um estudo de caso que está inserido no campo pesquisa-ação, por seu caráter participativo e por realizar uma intervenção em uma realidade específica (DEITOS, 2018, p. 19).
\end{abstract}

Nesse sentido vê-se que a autora utiliza a metodologia ativa em conjunto com o método tradicional, o ditado "qualquer texto oralizado, isto é, ditado em voz alta pelo professor para os alunos reproduzirem por escrito" (DEITOS, 2018, p. 24) numa junção da metodologia tradicional, das metodologias ativas (o jogo) e das notas tecnologias de informação e comunicação (TICS) [...] A problematização, jogos e a simulação podem levar ao contato com as informações e à produção do conhecimento, principalmente, com a finalidade de solucionar os impasses e promover o seu próprio desenvolvimento (DEITOS, 2018, p. 25).

A partir das adaptações práticas da pesquisadora enquanto alfabetizadora, percebeu que o ditado tradicionalmente utilizado para desenvolvimento do ensino 
aprendizagem da linguagem escrita, causava frustrações nos estudantes quando se deparavam com os erros sem compreendê-los.

Nesse sentido, o trabalho analisado abordou a tecnologia aplicada à educação a partir de um jogo digital de ditado, onde o objetivo é a aprendizagem da escrita e da ortografia de crianças do Ensino Fundamental abordando benefícios que a atividade o ditado considerado uma atividade tradicional disponibiliza ao ser inserido no contexto tecnológico.

Ao refletir o processo de ensino e aprendizagem matemática nos anos iniciais do ensino fundamental, vê-se que está totalmente ligada ao processo de alfabetização visto que, para a aprendizagem do ensino da matemática necessita a interpretação dos problemas para definição dos caminhos a serem seguidos e operações a serem utilizadas para resolução de problemas.

Portanto, o jogo como metodologia ativa, pode ser um grande aliado na construção da aprendizagem da linguagem escrita, podendo estar associado ao método tradicional associado as metodologias ativas, onde um não precisa necessariamente excluir o outro.

Compreender o erro e trabalhar a partir dele consiente de que é parte essencial do processo de aprendizagem, ressignificam os objetivos do uso das metodologias ativas no processo e ensino aprendizegm.

O segundo tipo de metodologia ativa encontrado foi uma dissertação, que trata da alfabetização pelo método de instrução por pares. Essa dissertação cujo título é "A Interação Grupal entre Pares e sua Repercussão no Processo de Construção da LectoEscrita", trata dessa metodologia a partir do interacionismo e apresenta pontos positivos desse método. Dessa forma a dissertação teve os objetivos de acompanhar a evoluçao conceitual possibilitada pela adaptação dessa pratica:

O estudo teve como objetivo compreender qual a repercussão da interação grupal entre pares na construção da lecto-escrita, investigando, portanto, a evolução conceitual acerca da compreensão de crianças em processo de alfabetização inicial que compartilhavam concepções com seus colegas e de crianças que não compartilhavam essa mesma proposta pedagógica (ISAIA, 2008, p. 13).

Educação, Psicologia e Interfaces, Volume 3, Dossiê Inclusão e Diversidade, p. 23-36, 2019.

ISSN: 2594-5343. DOI: https://doi.org/10.37444/issn-2594-5343.v3i4.198 
No caso da alfabetização esse método, associado às metodologias ativas possibilita a compreensão do som das letras, imagens e associação por figuras, no entanto ao solicitar que os educandos venham apenas com duvidas após tentar resolver e no caso de a alfabetização ler sozinhos, diante das dificuldades os alunos podem se retrair, apesar de que isso vai depender da forma como será proposta.

A aprendizagem por pares, propõe a interação para o desenvolvimento do ensino e aprendizagem, interação humana para construção do conhecimento numa forma de inovação das formas de ensino ao desafiar os estudantes.

Essa metodologia orienta que os estudantes devem ir para as aulas com as leituras previamente interpretadas, e com base nas informações básicas dos textos e conteúdos as aulas partiam de discussões e os estudantes poderiam levantar hipóteses e tirar dúvidas acerca dos assuntos:

Quando se discute com os colegas de classe sobre o tema, a compreensão era facilitada. Assim a técnica foi formalizada e passou a ser utilizada em sua sala de aula, sendo chamada de aprendizagem por pares, pensando na aprendizagem colaborativa (MOURA, 2017, p. 30).

$\mathrm{Na}$ metodologia de estudos por pares a participação ativa nas aulas torna o estudante centro da aprendizagem, o professor assume o papel de mediador, fazendo com que todos estudantes participem do processo de construção do conhecimento, como propõe as metodologias ativas:
A instrução pelos pares e uma outra metodologia ativa e tem o formato diferente da PBL, antes da aula os alunos precisam estudar sozinhos os materiais da aula indicados pelo professor. A aula começa com uma breve exposição, em torno de dez a 15 min sobre um dos tópicos que o professor quer desenvolver naquela aula. Depois ele apresenta uma questão de múltipla escolha e dos alguns minutos para os educandos pensarem e responderem individualmente (AGUIAR, 2008, p. 65).

Todos os estudantes devem participar de todas as atividades propostas apesar de qualquer dificuldade encontrada, dessa forma se percebe que apesar de não enfatzizar a politica de educação inclsuiva, essa metodologia se mostra inclusiva, ao tratar que todos devem participar e levantar hipóteses acerca do estudo para a resolução das atividades. Servindo a interação entre a turma servem para sanar dúvidas:

A aprendizagem por pares "é um método de aprendizagem ativa que possui dois objetivos básicos: explorar a interação entre os

Educação, Psicologia e Interfaces, Volume 3, Dossiê Inclusão e Diversidade, p. 23-36, 2019. ISSN: 2594-5343. DOI: https://doi.org/10.37444/issn-2594-5343.v3i4.198 
estudantes e focar sua atenção nos conceitos fundamentais para a resolução de questionamentos propostos em sala (ARAÚJO, 2017, p. 2401).

Essa metodologia desenvolve habilidades sociais, intelectuais, interpessoais e competências que colocam o estudante como protagonista de sua aprendizagem e viabiliza o desenvolvimento da autonomia e confiança em relação aos desafios na sociedade.

$\mathrm{Na}$ aprendizagem, grande parte dos conhecimentos são assimilados ao ensinar alguém, sendo benéfico tanto para quem ensina, quanto para quem apende, no caso a aprendizagem entre os alunos na sala de aula "[...] a dinâmica do método, além de despertar o interesse, motiva os alunos a se envolverem de forma a aprimorar a argumentação, a comunicação oral e o senso crítico" (MOURA, 2017, p. 68).

Portanto a aprendizagem por pares, propõe que os alunos auxiliem uns aos outros no desenvolvimento de atividades, onde os colegas que compreenderam melhor, mostram aos colegas os caminhos percorridos, construindo o conhecimento por pares.

As metodologias ativas como estratégias para o ensino aprendizagem, não são algo relativamente novo, os primeiros indícios da utilização de métodos ativos pode ser encontrado na obra Emílio de Jean Jacques Rosseau (1712-1778), primeiro a tratar sobre filosofia e educação do mundo ocidental.

Dewey, por meio do seu ideal da Escola Nova, teve importante influência nas metodologias ativas ao defender a ocorrência da aprendizagem pela ação, com o estudante como centro dos processos de ensino e de aprendizagem.

A proposta educativa de Freire (2015) corrobora com a abordagem das metodologias ativas bisto que de acordo com ele um dos grandes problemas no processo de escolarização ee o fato dos educandos não terem por vezes estimulos para o desenvolvimento do pensamento e consequentemente da autonomia.

As metodologias ativas incitam a refletir acerca de diversos caminhos existentes partindo do livro didático ou até mesmo chegar para além do livro didático. Quando o professor passa a incorporar o uso das metodologias ativas um passo essencial ee assumir uma postura de avaliação diagnostica de sua própria prática afim de refletir sobre e autoreconhecer problemas para propor soluções:

Ele não conhece de antemão a solução dos problemas que surgirão em sua prática; deve construí-la constantemente ao vivo, às vezes, com

Educação, Psicologia e Interfaces, Volume 3, Dossiê Inclusão e Diversidade, p. 23-36, 2019.

ISSN: 2594-5343. DOI: https://doi.org/10.37444/issn-2594-5343.v3i4.198 
grande estresse, sem dispor de todos os dados de uma decisão mais clara. Isso não pode acontecer sem saberes abrangentes, saberes acadêmicos, saberes especializados e saberes oriundos da experiência (Perrenoud, 2002, p. 11).

Uma das principais bases epistemológicas dessa corrente teórica são de Lev Vygotsky, que concebeu uma perspectiva social ao interativismo, para ele a interação social é o principal estimulo para o desenvolvimento do indivíduo de modo geral.

Vygotsky considera que a aprendizagem ocorre dentro da zona de desenvolvimento proximal, que é a distância entre o nível de desenvolvimento cognitivo real do indivíduo (capacidade de resolver problemas independentemente) e o nível de desenvolvimento potencial (capacidade de resolução de problemas sob orientação de um adulto) (Moreira, 2011).

O educador que adota essa concepção coloca o estudante como principal responsável pelo processo de ensino aprendizagem e passa a ser corresponsável pelo aprendizado do aluno. A visão interacionista faz com quem o professor entenda a aula como um espaço no qual, a voz do educando deva ser ouvida afim de constituir-se como sujeito da sua aprendizagem (Oliveira, 2010, p. 29).

Dessa forma a utilização do jogo da forma como foi identificada na dissertação, utiliza o ditado que é uma metodologia utilizada na escola tradicional, mas de forma conceitualizada. Essa forma contextualizada, apresenta pratica o ditado depois enfatiza a aprednizgame a partir do erro, essa e uma pratica que se apresenta como nova, visto que o erro historicamente e isto como algo negativo

Já na instrução por pares a dissertação analisada traz a interação como aspecto fundamental para ensino e aprendizagem da linguagem escrita, quando parte de interesse dos educanos para elaboração da pratica. Nessa perspectiva a pratica ee elaborada a partir do diagnistico de interesses da maioria da turma o que se apreneta para despertar os interesses dos estudantes nas praticas de ensino aprendizagem.

\section{CONSIDERAÇÕES FINAIS}

A perspectiva teórica designada é ointeracionismo simbólico, ao qual é atribuido significados aos símbolos no processo de comunicação para aprendizagem humana e dessa forma o trabalho sob a análise interacionista, busca relacionar os símbolos e a interação, verificando as formas como os significados surgem no contexto do comportamento. 
O trabalho coletivo deve ser desenvolvido com o intuito de facilitar a vida de todos, promovendo tarefas coletivamente para que todos auxiliem na resolução dos problemas, Panitz (1999) conceitua a aprendizagem pelas metodologias ativas sob a epistemologia construtivista que permite que os educandos questionem sobre o que estão estudando, passando a ser ator principal de sua aprendizagem "[...] A aprendizagem colaborativa é mais que uma técnica usada em sala de aula, mas uma filosofia de vida em que a pessoa, quando em grupo, compartilha seus conhecimentos, respeitando a opinião do outro e valorizando a capacidade de cada membro" (PANITZ, 1999, p. 65).

Na perspectiva da alfabetização, a a metodologia ativa deve ser embasada a partir do conteúdo gramatical, ortográfico e de fatos históricos, dessa forma são melhores aprendidos no primeiro ciclo da educação das crianças, ou seja, nos anos iniciais do ensino fundamental.

No presente estudo foram analisados dois tipos de metodologias ativas, o jogo e a instrução por pares. Foi possível observar que todas as estratégias utilizadas e exemplos de trabalho partem primeiramente de umaavaliaçao diagnóstica, no caso do jogo e ditado serve como compreende uma pratica afim de estabelecer a compreensão do erro, que na escola tradicional e visto como algo negativo, mas nas metodologias ativas e um dos primeiros passo para a aprendizagem, a compreensão do erro. Apesar desse método ser um pratica tradicional, quando adaptado e ressignificado se mostra eficaz como sempre foi visto, porque apesar de o ensino tradicional estar estereotipado, professores mestres e doutores da atualidade aprenderam nessa base, que não esta de todo errada.

O foco deve estar nas potencialidades dos estudantes, com formas alternativas para superar barreiras apresentadas pelos estudantes. Ao buscar estratégias para que o grupo, coletivamente, tome conhecimento dos conteúdos que estão sendo ministrados, a metodologia ativa realiza uma intervenção na realidade vivenciada pelos estudantes.

Nesse sentido resultado dessa pesquisa foi que os alunos persistem nas atividades até chegar ao acerto, porque não são oprimidos diante do mesmo, portanto se mostra eficaz ao incluir cada participante independente das dificuldades encontradas, por isso a metodologia ativa é uma tendência através da percepção de suas contribuições na construção do conhecimento da linguagem escrita.

\section{REFERÊNCIAS BIBLIOGRÁFICAS}

Educação, Psicologia e Interfaces, Volume 3, Dossiê Inclusão e Diversidade, p. 23-36, 2019.

ISSN: 2594-5343. DOI: https://doi.org/10.37444/issn-2594-5343.v3i4.198 
AGUIAR, Andrea Pisan Soares. Metodologias Ativas: Aprendizagem Baseada em Problemas, Problematização e Método do Caso. Brazilian Journal of Education, Technology and Society (BRAJETS) 2008. http://dx.doi.org/10.14571/brajets.v11.n3 Acesso em: 10/ 2019

ARAUJO, Alexandre Alberto Visentin Ramos. Uma associação do método Peer Instruction com circuitos elétricos em contextos de aprendizagem ativa. Revista Brasileira de Ensino de Física, v. 39, n. 2, p. e2401, 2017.

BERGMANN, J.; SAMS, A. Sala de aula invertida: uma metodologia ativa de aprendizagem. Rio de Janeiro: LTC, 2016.

CARVALHO, Sonia Souza. O Jogo Como Recurso Para O Ensino Da Leitura A Estudantes Com Deficiência Intelectual' 12/08/2015 120 F. Mestrado Profissional Em Letras Instituição De Ensino: Universidade Estadual Do Sudoeste Da Bahia, Natal Biblioteca Depositária: biblioteca da UESB. Disponivel em https://sucupira.capes.gov.br/sucupira/public/consultas/coleta/trabalhoConclusao/viewT rabalhoConclusao.jsf?popup=true\&id_trabalho=3601478 Acesso em: 10/ 2019

DEITOS, Fernanda Nunes. Jogo De Ditado Digital: O Erro Como Parte Do Processo de Aprendizagem. Disponível em https://sucupira.capes.gov.br/sucupira/public/consultas/coleta/trabalhoConclusao/viewT rabalhoConclusao.jsf?popup=true\&id_trabalho=7431848 Acesso em: 10/ 2019

DEWEY, John. Vida e educação. 10. ed. São Paulo: Melhoramentos, 1978.

FREIRE, Paulo. Pedagogia da Autonomia. Saberes necessários à prática educativa. 51ª ed. Rio de Janeiro: Paz e terra, 2015.

FREITAS, C. M. Uso de metodologias ativas de aprendizagem para a educação na saúde: análise da produção científica. Trabalho, Educação e Saúde, Rio de Janeiro, v.13, supl.2, p.117-130, 2015.

GIL, Antônio Carlos. Métodos e técnicas de pesquisa social / Antonio Carlos Gil. - 6. ed. - São Paulo: Atlas, 2008. ISBN 978-85-224-5142-5 Disponível em https://ayanrafael.files.wordpress.com/2011/08/gil-a-c-mc3a9todos-e-tc3a9cnicas-depesquisa-social.pdf Acesso em: $10 / 2017$

ISAIA, Tatiane Peixoto. A Interação Grupal Entre Pares E Sua Repercussão No Processo De Construção Da Lecto-Escrita. 2008. Disponível em: https://repositorio.ufsm.br/bitstream/handle/1/6808/TATIANEPEIXOTOISAIA.pdf?seq uence $=1 \&$ isAllowed=y Acesso em: 10/ 2019.

MOURA, Bruna Ligabo de. Application of Peer Instruction in Mathematics for fifth grade students of elementary school. 2017. 74 p. Dissertation (Master of Science) Escola de Engenharia de Lorena, Universidade de São Paulo, Lorena, 2017. Acesso em: 06/ 2019. 
MOREIRA, Marco A. Aprendizagem significativa: a teoria e textos complementares. São Paulo: Livraria da Física, 2011a. Teorias de aprendizagem. 2. ed. São Paulo: EPU, 2011.

OLIVEIRA, Luciano Amaral. Coisas que todo professor de português precisa saber: a teoria na prática. São Paulo: Parábola Editorial, 2010.

PANITZ, T. Collaborative versus Cooperative Learning: A Comparison of the Two Concepts, Which Will Help Us, Understand the Underlying Nature of Interactive Learning. Maryland: ERIC, 1999, p. 1-13.

PEREIRA, Rodrigo. Método Ativo: Técnicas de Problematização da Realidade aplicada à Educação Básica e ao Ensino Superior. In: VI Colóquio internacional. Educação e Contemporaneidade. São Cristóvão, SE. 20 a 22 setembro de 2012.

PERRENOUD, Philippe. A prática reflexiva no ofício de professor: profissionalização e razão pedagógica. Porto Alegre: Artmed, 2002.

PIAGET, Jean (1990). A Formação do Símbolo na criança. Editora: Livros técnicos e científicos. Disponível em:

http://www.saosebastiao.sp.gov.br/ef/pages/Corpo/Habilidades/leituras/a1.pdf Acesso em: 10/ 2019

SORIANO, Karen Regiane. Efeitos de Histórias Adaptadas na Produção de Narrativas Orais de uma Criança com Baixa Visão em Idade Pré-Escolar' 07/03/2017 161 f. Mestrado em EDUCAÇÃO Instituição de Ensino: Universidade Estadual Paulista Júlio De Mesquita Filho, Marília Biblioteca Depositária: Campus de Marília. Disponível em:

https://sucupira.capes.gov.br/sucupira/public/consultas/coleta/trabalhoConclusao/viewT rabalhoConclusao.jsf?popup=true\&id_trabalho=5038119 Acesso em: 10/ 2019

SOUSA, Mapoanney Nhalis Clares. Conhecimento de discentes sobre metodologia ativa na construção do processo de ensino aprendizagem inovador. Revista Interdisciplinar Encontro das Ciências-RIEC| ISSN: 2595-0959|, v. 1, n. 1, p. 61-74, 2018.

VYGOTSKY, L.S. A formação social da mente. São Paulo: Martins Fontes, 1987.

Credenciais da/os autora/es

DIAS, Nelson. Prof ${ }^{\circ}$ Mestre e Doutorando em Ensino de Ciências pelo Programa de Pósgraduação em Ensino de Ciências da Universidade Federal de Mato Grosso do Sul. Professor de LIBRAS na Universidade Federal de Mato Grosso do Sul.- UFMS - Campus Ponta Porã, graduado em Ciências Biológicas (UFMS). E-mail: nelsonufms@ hotmail.com

Educação, Psicologia e Interfaces, Volume 3, Dossiê Inclusão e Diversidade, p. 23-36, 2019. ISSN: 2594-5343. DOI: https://doi.org/10.37444/issn-2594-5343.v3i4.198 
Endereço para correspondência: Universidade Federal de Mato Grosso do Sul, CPPP - Câmpus Ponta Porã - Rua Itibiré Vieira, Km 4.5, S/n - Res. Julia de Oliveira Cardinal, Ponta Porã - MS - Brasil.79907-414.E-mail: nelsonufms@ hotmail.com

SILVA, Édna Leandro da. Mestranda do Programa de Pós-graduação em Educação da Universidade Federal de Mato Grosso do Sul, graduada em Pedagogia (UFMS), Especialista em Psicopedagogia Institucional Clínica e Educação Especial. E-mail: edna.silva5666@gmail.com

Endereço para correspondência: Edna Leandro da Silva, Rua Lourdes Maria Flores $n^{\circ}$ 56, Bairro Ramez Tebet CEP 79073306, Campo Grande/MS- Brasil. E-mail: edna.silva5666@gmail.com

Como citar este artigo (Formato ABNT): SILVA, Édna Leandro da; DIAS, Nelson. Alfabetização de alunos com deficiência intelectual a partir de Metodologias Ativas. Educação, Psicologia e Interfaces, v. 3, Dossiê Inclusão e Diversidade, p. 23-36, 2019. DOI: https://doi.org/10.37444/issn-2594-5343.v3i4.198

Recebido: 30/10/2019.

Aceito: 20/11/2019. 